\title{
Ultrasound guided needle biopsy of axilla to evaluate nodal metastasis after preoperative systemic therapy in cohort of 106 breast cancers enriched with BRCA1/2 pathogenic variant carriers
}

Baiba Līcite ${ }^{1,2^{*}}$, Arvīds Irmejs ${ }^{1,2,3}$, Jel̦ena Maksimenko ${ }^{1,2,3}$, Pēteris Loža ${ }^{1,2}$, Genādijs Trofimovičs ${ }^{1,2}$, Edvīns Miklaševičs ${ }^{3}$, Jurijs Nazarovss ${ }^{4}$, Māra Romanovska ${ }^{4}$, Justīne Deičmane ${ }^{5}$, Reinis Irmejs ${ }^{6}$, Gunta Purkalne ${ }^{1,7}$ and Jānis Gardovskis ${ }^{1,2,3}$

\begin{abstract}
Background: Aim of the study is to evaluate the role of ultrasound guided fine needle aspiration cytology (FNAC) in the restaging of node positive breast cancer after preoperative systemic therapy (PST).

Methods: From January 2016 - October 2020106 node positive stage IIA-IIIC breast cancer cases undergoing PST were included in the study. 18 (17\%) were carriers of pathogenic variant in BRCA1/2. After PST restaging of axilla was performed with ultrasound and FNAC of the marked and/or the most suspicious axillary node. In 72/106 cases axilla conserving surgery and in 34/106 cases axillary lymph node dissection (ALND) was performed.

Results: False Positive Rate (FPR) of FNAC after PST in whole cohort and BRCA1/2 positive subgroup is 8 and $0 \%$ and False Negative Rate (FNR) - 43 and $18 \%$ respectively. Overall Sensitivity - 55\%, specificity- $93 \%$, accuracy $70 \%$. Conclusion: FNAC after PST has low FPR and is useful to predict residual axillary disease and to streamline surgical decision making regarding ALND both in BRCA1/2 positive and negative subgroups. FNR is high in overall cohort and FNAC alone are not able to predict ypCR and omission of further axillary surgery. However, FNAC performance in BRCA1/2 positive subgroup is more promising and further research with larger number of cases is necessary to confirm the results.
\end{abstract}

Keywords: Breast cancer neoadjuvant axilla cytology BRCA1/2

\footnotetext{
* Correspondence: baiba.licite@gmail.com

'Department of Surgery, Riga Stradinš̌ University, Pilsoṇu iela 13, LV-1002

Riga, Latvia

${ }^{2}$ Department of Surgery, (Affiliated Partner of the European Reference

Network on Genetic Tumour Risk Syndromes (ERN GENTURIS)), Pauls Stradiņ̌̌

Clinical University Hospital, Pilsonu iela 13, LV-1002 Riga, Latvia

Full list of author information is available at the end of the article
}

C C The Author(s). 2021 Open Access This article is licensed under a Creative Commons Attribution 4.0 International License, which permits use, sharing, adaptation, distribution and reproduction in any medium or format, as long as you give appropriate credit to the original author(s) and the source, provide a link to the Creative Commons licence, and indicate if changes were made. The images or other third party material in this article are included in the article's Creative Commons licence, unless indicated otherwise in a credit line to the material. If material is not included in the article's Creative Commons licence and your intended use is not permitted by statutory regulation or exceeds the permitted use, you will need to obtain permission directly from the copyright holder. To view a copy of this licence, visit http://creativecommons.org/licenses/by/4.0/. The Creative Commons Public Domain Dedication waiver (http://creativecommons.org/publicdomain/zero/1.0/) applies to the data made available in this article, unless otherwise stated in a credit line to the data. 


\section{Background}

According to recent studies pathological complete response (pCR) after neoadjuvant chemotherapy (NAC) in node positive breast cancer is observed in up to $40-75 \%$ of cases [1-4]. BRCA1 positive breast cancer subgroup also has high rate of $\mathrm{pCR}$ - up to $61 \%$ [5]. It means that preoperative systemic therapy has completely eliminated all regional cancer involvement and total removal of all axillary lymph nodes is not justified. However, until recently axillary lymph node dissection (ALND) was performed in all node positive cases irrespective of response to PST. According to latest NCCN guidelines for breast cancer, conservation of axilla should be considered, if nodes are clinically negative after PST, but optimal axillary management after PST is still not known [6, 7]. Several preoperative and intraoperative axillary reevaluation approaches have been studied recently including physical examination, imaging (e.g. ultrasound, PET-CT) and biopsy techniques $[8,9]$. Imaging studies of $\mathrm{PET} / \mathrm{CT}$ is controversial for axillary staging after PST [10]. Combined clipped and sentinel node biopsy approach has very low false negative rate $1,4 \%$, but disadvantage is necessity of intraoperative frozen section and/or potential for repeated axillary surgery in $\mathrm{cN} 2$ and $\mathrm{cN} 3$ cases [9].

FNAC or core needle biopsy has been widely used for initial evaluation of axillary nodal status in case of breast cancer, but to the best of our knowledge there are only two small series (including our earlier one), which are reporting on axillary lymph node FNAC accuracy after PST $[11,12]$. Aim of the study is to further evaluate the role of FNAC in the restaging of node positive breast cancer after PST, including subgroup of BRCA1/2 positive cases.

\section{Materials and methods}

Prospective cohort study was carried out at the state tertiary healthcare institution. This study was approved by the Pauls Stradiňš Clinical Univerity hospital Development Society Clinical Research Ethics Committee (310816-12 L) and Riga Stradiňš University Research Ethics Committe $(72 / 29.10 .2015$.) All participants provided written informed consent.

From January 2016 - October 2020106 FNAC confirmed node positive stage IIA-IIIC breast cancer cases undergoing PST were recruited to the study, including $18(17 \%)$ carriers of pathogenic variant in BRCA1 (2$300 \mathrm{~T}>\mathrm{G}, 5$ - 4154delA, 7-5382insC, 2- c.5117G > A, 1del exon20) and BRCA2 (1- 9097delA). All patients were female with median age of 51 years (range 25-75 years).

$18 / 106$ (17\%) of cases belonged to HER2 positive subtype, 24/106 (23\%) were triple negative (TN) and 64/ 106 (60\%) Luminal. 17/106 (16\%) cases were Luminal HER2 positive. Cases are considered as TN if HER2 is negative and estrogen/progesteron is <10\%. 100/106
(94\%) had ductal, 5/106 (5\%) cases - lobular and 1/106 (1\%) combined pathology.

According to study protocol both before and after PST fine needle aspiration (FNA) was performed if at least one lymphnode on ultrasound had cortex $>3 \mathrm{~mm}$ or absence of fatty hilum was present irrespective of lymphnode size. In case of several lymphnodes with the suspicious features, one with the most prominent changes and/or the most accessible from technical perspective was chosen.

FNA procedure was performed following the technique described by Dusenbery, 1997. Once the needle was in lymphnode, suction was applied to the syringe and the needle tip was moved back and forth within the node. On average 10 to 20 excursions with the needle were performed before obtaining material in the hub of the needle.

In case of malignant finding in cytology, marker was introduced in affected lymphnode to facilitate restaging and targeted surgery of axilla. Initially $\mathrm{V}$-mark ${ }^{\mathrm{TM}}$ Breast Biopsy Site Marker with Titanium Anchor (Argon Medical Devices, Inc) were used, but later were changed to Hydromark clips, which have better visualization capacities under ultrasound at least 6 months after insertion.

Targeted axillary ultrasound and FNA was carried out by three general surgeons with the specialization in breast surgery, who have successfully passed EBSQ (European Breast Surgery Qualification) exam and have underwent National Ultrasound method postgraduate courses. In all cases sampling was done by the same physician before and after PST. All samples were reviewed by one cytologist experienced in breast pathology.

$\mathrm{cN}$ stage was diagnosed on the basis of pretreatment imaging (ultrasound and CT) data. If 1-3 involved axillary nodes were identified - $\mathrm{cN} 1$ stage was classified. If more than 3 metastatic lymph nodes were visualized in axilla, then cN2 stage was set. If infra/supraclavicular lymph node metastasis or more than 10 affected axillary nodes were detected, then cN3 stage was diagnosed. Frequency of cN1, cN2 and $\mathrm{cN} 3$ stage was observed in 58 (55\%), 23 (22\%) and 25 (23\%) cases respectively.

After PST restaging of axilla was performed with ultrasound guided FNAC of the marked and/or the most suspicious axillary node. Nondiagnostic cases were not included. In 10/106(9\%) cases, deviation from study protocol took place as core biopsy technique was used instead of FNAC.

Modified algorithm of Netherlands cancer institute/ Antoni van Levenhoek hospital (NCI/AVL) was followed to decide on axilla conserving surgery (ACS) versus ALND as described by Koolen [4]. 72/106 axilla conserving surgeries (ACS) and 34/106 ALND were performed. Number of examined nodes in ACS group was 1-18, on 
average 6 and in ALND group 2-30, on average 13. Difference between retrieved nodes in ACS and ALND was statistically significant $(p<0.05)$.

In order to assess diagnostic value of ultrasound guided FNAC, FNR and FPR as well sensitivity, specificity, positive predictive value (PPV), negative predictive value (NPV) and accuracy were calculated. Statistical analyses were performed using Medcalc, easy-to-use software and MS Excel 2010. Fisher's exact test was used for comparison of the results between groups.

\section{Results}

Overall nodal pCR was observed in 41/106 (39\%) cases: Luminal - 19/64 (30\%); HER2 positive - 11/18 (61\%); TN - 11/24 (46\%). Distribution of nodal pCR in BRCA $1 / 2$ positive and negative subsets is $-9 / 18(50 \%)$ and 32/88 (36\%) respectively.

After PST FNAC revealed residual nodal cancer in 39/ $106(37 \%)$ cases, but in 67/106 (63\%) no malignancy was detected. In final surgical pathology in 65/106 (61\%) cases malignant cells persisted in axillary lymph nodes, but in 41/106 (39\%) cases no nodal tumor was detected after PST.

In 36/39 (92\%) cases, which had positive FNCA after PST, metastasis in axillary lymph nodes were revealed in the pathology examination of surgery specimen - ypN1mi, ypN1, ypN2 and ypN3 stage was detected in 1, 18, 11 and 6 cases respectively. Overall FPR of FNAC after PST is $3 /$ 39 (8\%). In contrary, only $38 / 67(57 \%)$ cases with negative lymph node FNAC after PST, turned out to be without nodal involvement in surgery specimen examination. 29 false negative cases in final pathology revealed ypNmi, ypN1, ypN2, ypN3 nodal status in 7, 18, 3 and 1 case respectively. Overall FNR of FNCA after PST is 29/67 (43\%). FNAC was able to predict nodal response to PST correctly in 74/106 (70\%) of cases.

Further subgroup analysis revealed that in case of BRCA1/2 positive breast cancers FPR was $0 \%(0 / 7)$ and FNR was $18 \%(2 / 11)$. In this subset FNAC was able to predict response to PST correctly in 16/18 (89\%) cases. Comparison of FNR between BRCA1/2 positive and BRCA1/2 negative subsets using Fisher's exact test revealed statistical difference very close to significant, $p$ value $=0,051502$, but difference between FNR in BRCA1/2 positive and Luminal subsets was statistically significant, $p=027096$.

Accuracy of FNAC test in TN, HER2 positive, Luminal and BRCA $1 / 2$ negative subgroups is $79 \%$, $78 \%, 64$ and $66 \%$ respectively. Detailed results of FPR, FNR, sensitivity, specificity, positive and negative predictive value as well accuracy of the test in different subgroups see in Table 1.

\section{Discussion}

Axillary pCR after PST is frequent event in case of breast cancer [1-4]. Also, in our cohort we report $39 \%$ of axillary pCR. Therefore, it is very important to perform appropriate restaging in node positive breast cancers after PST to avoid unnecessary ALND. One has to take in to account that there is no pertuzumab approved for PST in nonmetastatic setting in our country and with dual HER2 blockade pCR rate is expected to be even higher.

ACS, including clipped node biopsy alone or in combination with SNB has very low FNR $[4,9]$ and is very good approach to restage the axilla after PST, however in large proportion of node positive cases, especially cN2 and $\mathrm{cN} 3$ stage, still considerable residual nodal involvement remains, which requires ALND. One solution is frozen section, but it has several disadvantages: potentially prolonged surgery time and rather high FNR $33 \%$ [13]. It means that considerable proportion of cases potentially could require repeated surgery to perform ALND and it is not ideal management neither from patient nor hospital perspective. Therefore, it is important to have accurate diagnostic tools for axilla restaging preoperatively.

There are data on effectiveness of axillary ultrasound and FNAC to evaluate nodal status prior breast cancer treatment as well evaluation of ultrasound method alone after PST $[14,15]$. However to the best of our knowledge there are only two small series (including our earlier one), which are reporting on axillary lymph node FNAC accuracy after PST $[11,12]$. In our present study false negative

Table 1 FPR, FNR, sensitivity, specificity, positive and negative predictive value as well accuracy of the FNAC test

\begin{tabular}{lllllll}
\hline & Overall & BRCA & Non BRCA & TN & HER2+ & Luminal \\
\hline FPR\% & $8(3 / 39)$ & $0(0 / 7)$ & $9(3 / 32)$ & $0(0 / 8)$ & $0(0 / 3)$ & $11(3 / 28)$ \\
FNR\% & $43(29 / 67)$ & $18(2 / 11)$ & $48(27 / 56)$ & $31(5 / 16)$ & $27(4 / 15)$ & $56(20 / 36)$ \\
Sensitivity\% & 55.38 & 77.78 & 51.79 & 61.54 & 42.86 & 55.56 \\
Specificity\% & 92.68 & 100 & 90.62 & 100 & 100 & 84.21 \\
Positive Predictive Value\% & 92.31 & 100 & 90.63 & 100 & 68.75 & 73.33 \\
Negative Predictive Value\% & 56.72 & 81.82 & 51.79 & 79.17 & 77.78 & 44.44 \\
Accuracy\% & 69.81 & 88.89 & 65.91 & & 64.06 \\
\hline
\end{tabular}


rate of FNCA after PST is $43 \%$, sensitivity - $55.38 \%$ and negative predictive value $-56.72 \%$. False positive rate is $8 \%$ and specificity of the test is $92.68 \%$. Accuracy of test is $69.81 \%$. Obtained data are similar to those reported by Caudle et al.: sensitivity of $42.4 \%$, specificity of $100 \%$, and negative predictive value of $40.6 \%$. In the studies, which have evaluated the diagnostic value of axillary FNAC prior to PST, reported sensitivity, specificity and accuracy lies between 41 and $80 \%, 96-100 \%$ and $70-89 \%$ respectively, but methodological differences exist [16-22]. We can conclude that in our study sensitivity of the FNAC is close to lowest range reported, but specificity and accuracy is clearly lower. One can conclude that accuracy of axillary FNAC after PST is somewhat lower than prior to PST. Low sensitivity of axillary FNAC together with high FNR in this setting precludes the omission of axillary surgery in spite of negative cytology. However, low FPR and specificity of the test is high enough to streamline surgical care with ALND for node-positive patients with considerable residual cancer burden expected. This approach has a potential to avoid frozen section and repeated axillary surgery in particular cases.

There are also report that sensitivity and specificity of axillary ultrasound alone after PST are 55 and $88 \%$, respectively, which is very close to results of our research [23-25]. However pathological confirmation of $\mathrm{ycN}$ stage is very important in surgical decision making especially taking in to account that ultrasound method is highly operator dependent.

In spite of high overall FNR, it is considerably lower in BRCA $1 / 2$ positive subgroup in comparison to BRCA $1 / 2$ negative subgroup ( $18 \%$ vs. $48 \%$ ). This difference is very close to reach statistical significance and difference between FNR in BRCA1/2 positive and Luminal subgroups ( $18 \%$ vs. $56 \%$ ) is statistically significant. Reasons for this potential finding are not completely clear, but could be related to the more homogenous patterns of nodal response to PST in case of BRCA1/2 carriers. However larger numbers are required to confirm this finding and potential for omission of axillary surgery in this subgroup on the basis of percutaneous biopsy only.

Like other studies we report significantly lower axillary pCR rate in Luminal subtype breast cancers [1]. Lobular breast cancers have extremely low rates of $\mathrm{pCR}$ after PST, but there are only 5/106 lobular cancer cases in our cohort and we are not into position to make any statements on this [26].

One of the potential biases of the study is inclusion of small number of core needle biopsy cases as well. For a short period of time it was allowed for responsible surgeon to choose between FNAC or core needle biopsy. However, according to literature data there is no considerable diagnostic value differences, but we presume that $\mathrm{CNB}$ is associated with smaller percentage of uninformative samples and repeated procedures respectively [27].

Another potential cause of bias - interobserver variability should be mentioned [28].

Present literature evidence continues to recommend FNAC as the most sensitive screening for breast cancer metastases in the axillary region. However, one should also mention innovative vacuum assisted breast biopsy (VABB) technologies, which could be considered in future studies. To the best of our knowledge there are no literature date on the use of this method to evaluate axillary lymph nodes after PST [29].

There are also number of calculation tools available to predict status of sentinel node in case of breast cancer with clinically negative axilla. However, as showed by experimental results by Fanizzi et al., CancerMath is not particularly suitable for use as a support instrument for the prediction of metastatic lymph nodes on clinically negative patients. And again, it should be emphasized that those tools are not validated in patients after PST, which is the target group of our study [30].

In our research we used only Gray-scale ultrasound. To improve gray-scale ultrasound results, some of the authors offer to use contrast-enhanced ultrasound (CEUS), elastography or colour Doppler. A systematic review and meta-analysis shows CEUS-guided core biopsy sensitivity $54 \%$ and specificity $100 \%$ in cases with normal axillary gray-scale ultrasound [31].

In another study grey-scale ultrasound was compared to elastography. Sensitivity and specificity for grey-scale ultrasound in detecting malignant nodes (defined by a cortical thickness $>3 \mathrm{~mm}$ ) were 40 and $97 \%$. Sensitivity and specificity for elastography were 60 and $80 \%$. When grey-scale ultrasound and elastography were combined, the sensitivity and specificity rose to 73 and $99 \%$, respectively [32].

In spite of controversial reports, there are number of additional tools to be considered for future studies to improve axillary restaging after PST [33].

\section{Conclusions}

FNAC after PST has low FPR and is useful to predict residual axillary disease and to streamline surgical decision making regarding ALND both in BRCA1/2 positive and negative subgroups. FNR is high in overall cohort and FNAC alone are not able to predict ypCR and omission of further axillary surgery. However, FNAC performance in $B R C A 1 / 2$ positive subgroup is more promising and further research with larger number of cases is necessary to confirm the results.

\section{Abbreviations}

FNAC: Fine needle aspiration cytology; PST: Preoperative systemic therapy; ALND: Axillary lymph node dissection; ACS: Axilla conserving surgery; 
FPR: False Positive Rate; FNR: False Negative Rate; pCR: Pathological complete response; NAC: Neoadjuvant chemotherapy; NCA/AVL: Netherlands cancer institute/Antoni van Levenhoek hospital; TN: Triple negative; PPV: Positive predictive value; NPV: Negative predictive value

\section{Acknowledgements}

"This research is supported (not financially) by the European Reference Network on Genetic Tumour Risk Syndromes (ERN GENTURIS)_Project ID No 739547. ERN GENTURIS is partly co-funded by the European Union within the framework of the Third Health Programme "ERN-2016_Framework Partnership Agreement 2017-2021".

\section{Authors' contributions}

The author(s) read and approved the final manuscript.

\section{Authors' information}

Not applicable.

\section{Funding}

Not applicable.

\section{Availability of data and materials}

The datasets generated during and/or analyzed during the current study are available from the corresponding author on reasonable request.

\section{Declarations}

\section{Ethics approval and consent to participate}

This study was approved by the Pauls Stradinš Clinical Univerity hopital Development Society Clinical Research Ethics Committee (310816-12 L) and Riga Stradinš University Research Ethics Committe (72/29.10.2015.) All participants provided written informed consent.

\section{Consent for publication}

Not applicable.

\section{Competing interests}

The author declare that they have no competing interests.

\section{Author details}

'Department of Surgery, Riga Stradinš University, Pilsonu iela 13, LV-1002 Riga, Latvia. ${ }^{2}$ Department of Surgery, (Affiliated Partner of the European Reference Network on Genetic Tumour Risk Syndromes (ERN GENTURIS)), Pauls Stradinš̌ Clinical University Hospital, Pilsoṇu iela 13, LV-1002 Riga, Latvia. ${ }^{3}$ Institute of Oncology, Riga Stradinš University, Pilsonu iela 13, LV-1002 Riga, Latvia. ${ }^{4}$ Department of Pathology, Pauls Stradiņš Clinical University Hospital, Pilson,u iela 13, LV-1002 Riga, Latvia. ${ }^{5}$ Department of Radiology, Pauls Stradinš Clinical University Hospital, Pilsonu iela 13, LV-1002 Riga, Latvia. 'St John's College, University of Cambridge, Cambridge, England. '7Department of Oncology, Pauls Stradinš Clinical University Hospital, Pilsonu iela 13, LV-1002 Riga, Latvia.

Received: 3 February 2021 Accepted: 18 June 2021

Published online: 07 July 2021

\section{References}

1. Boughey JC, McCall LM, Ballman KV, Mittendorf EA, Ahrendt GM, Wilke LG, Taback B, Leitch AM, Flippo-Morton T, Hunt KK. Tumor biology correlates with rates of breastconserving surgery and pathologic complete response after neoadjuvant chemotherapy for breast cancer findings from the ACOSOG Z1071 (alliance) prospective multicenter clinical trial. Ann Surg. 2014;260(4):608-16. https://doi.org/10.1097/SLA.0000000000000924.

2. Diego EJ, McAuliffe PF, Soran A, McGuire KP, Johnson RR, Bonaventura M, Ahrendt GM. Axillary Staging After Neoadjuvant Chemotherapy for Breast Cancer: A Pilot Study Combining Sentinel Lymph Node Biopsy with Radioactive Seed Localization of Pre-treatment Positive Axillary Lymph Nodes. Ann Surg Oncol. 2016;23(5):1549-53. https://doi.org/10.1245/s10434-015-5052-8.

3. Dominici LS, Gonzalez N, Buzdar VM, Lucci AU, Mittendorf A, Le-Petross EA, Babiera HT, Meric-Bernstam GV, Hunt F, Kuerer KK. H. M. Cytologically proven axillary lymph node metastases are eradicated in patients receiving preoperative chemotherapy with concurrent trastuzumab for HER2-positive breast cancer. Cancer. 2010;116(12):2884-9. https:/doi.org/10.1002/cncr.25152.

4. Koolen BB, Donker M, Straver ME, van der Noordaa MEM, Rutgers EJT, Valdés Olmos RA, Peeters V. M. J. T. F. D. Combined PET-CT and axillary lymph node marking with radioactive iodine seeds (MARI procedure) for tailored axillary treatment in node-positive breast cancer after neoadjuvant therapy. Br J Surg. 2017;104(9):1188-96. https://doi.org/10.1002/bjs.10555.

5. Byrski T, Huzarski T, Dent R, Marczyk E, Jasiowka M, Gronwald J, Jakubowicz J, Cybulski C, Wisniowski R, Godlewski D, Lubinski J, Narod SA. Pathologic complete response to neoadjuvant cisplatin in BRCA1-positive breast cancer patients. Breast Cancer Res Treat. 2014;147(2):401-5. https://doi.org/10.1007/ s10549-014-3100-x.

6. Breast Cancer Screening and. Diagnosis. Version 3.2018, NCCN Clinical Practice Guidelines in Oncology. https://doi.org/10.6004/jnccn.2018.0083 Accessed 22 Feb 2000

7. Vugts G, Maaskant-Braat AJG, de Roos WK, Voogd AC, Nieuwenhuijzen G. A. P. Management of the axilla after neoadjuvant chemotherapy for clinically node positive breast cancer: A nationwide survey study in The Netherlands. Eur J Surg Oncol. 2016;42(7):956-64. https://doi.org/10.1016/j.ejso.2016.03.023.

8. Boughey JC, Ballman KV, Hunt KK, McCall LM, Mittendorf EA, Ahrendt GM, Wilke LG, Le-Petross HT. Axillary ultrasound after neoadjuvant chemotherapy and its impact on sentinel lymph node surgery: Results from the American college of surgeons oncology group Z1071 Trial (Alliance). J Clin Oncol. 2015;33(30). https://doi.org/10.1200/JCO.2014.57.8401.

9. Caudle AS, Yang WT, Krishnamurthy S, Mittendorf EA, Black DM, Gilcrease MZ, Bedrosian I, Hobbs BP, Desnyder SM, Hwang RF, Adrada BE, Shaitelman SF, Chavez-MacGregor M, Smith BD, Candelaria RP, Babiera GV, Dogan BE, Santiago L, Hunt KK, Kuerer HM. Improved axillary evaluation following neoadjuvant therapy for patientswith node-positive breast cancer using selective evaluation of clipped nodes: implementation of targeted axillary dissection. J Clin Oncol. 2016; 34(10):1072-8. https://doi.org/10.1200/JCO.2015.64.0094.

10. Koolen BB, Pengel KE, Wesseling J, Vogel W, Peeters MJ, Vincent AD, Gilhuijs KG, Rodenhuis KG, Rutgers S, Valdés Olmos RA. Sequential 18F-FDG PET/CT for early prediction of complete pathological response in breast and axilla during neoadjuvant chemotherapy. Eur J Nucl Med Mol Imaging. 2014:41(1):32-40. https://doi.org/10.1007/s00259-013-2515-7.

11. Caudle AS, Kuerer HM, Krishnamurthy S, Shin K, Hobbs BP, Ma J, Mittendorf EA, Washington AC, DeSnyder SM, Black DM, Hunt K, Yang WT. Feasibility of fine-needle aspiration for assessing responses to chemotherapy in metastatic nodes marked with clips in breast cancer: A prospective registry study. Cancer. 2019;125(3):365-73. https://doi.org/10.1002/cncr.31825.

12. Licite B, Irmejs A, Maksimenko J, Loža P, Trofimovičs G, Miklaševičs E, Nazarovs J, Romanovska M, Deičmane J, Purkalne G, Gardovskis J. Role of Percutaneous Needle Biopsy of Axillary Lymph Nodes to Evaluate Node Positive Breast Cancer after Neoadjuvant Chemotherapy. Proceedings of the Latvian Academy of Sciences. Section B. Nat Exact Appl Sci. 2019;73(4):36872. https://doi.org/10.2478/prolas-2019-0057.

13. Akay CL, Albarracin C, Torstenson T, Bassett R, Mittendorf EA, Yi M, Kuerer HM, Babiera GV, Bedrosian I, Hunt KK, Hwang RF. Factors impacting the accuracy of intra-operative evaluation of sentinel lymph nodes in breast cancer. Breast J. 2018;24(1):28-34. https://doi.org/10.1111/tbj.12829.

14. Pesek SE, King HM, Koelliker S, Raker C, Edmonson D, Dizon DS, Gass J. Axillary Ultrasound Fine Needle Aspiration Biopsy: Is There a Role in the Post Z-0011 Era? Am J Clin Oncol. 2017;41(7):702-7. https://doi.org/10.1097/ COC.0000000000000345.

15. Vijayaraghavan GR, Vedantham S, Kataoka M, DeBenedectis C, Quinlan RM. The Relevance of Ultrasound Imaging of Suspicious Axillary Lymph Nodes and Fineneedle Aspiration Biopsy in the Post-ACOSOG Z11 Era in Early Breast Cancer. Acad Radiol. 2017;24(3):308-15. https://doi.org/10.1016/.jacra.2016.10.005.

16. Cools-Lartigue J, Meterissian S. Accuracy of axillary ultrasound in the diagnosis of nodal metastasis in invasive breast cancer: A review. World J Surg. 2012;36(1):46-54. https://doi.org/10.1007/s00268-011-1319-9.

17. Hieken TJ, Trull BC, Boughey JC, Jones KN, Reynolds CA, Shah SS, Glazebrook KN. Preoperative axillary imaging with percutaneous lymph node biopsy is valuable in the contemporary management of patients with breast cancer. Surgery (United States). 2013;154(4):831-40. https://doi.org/1 0.1016/j.surg.2013.07.017.

18. Ciatto S, Brancato B, Risso G, Ambrogetti D, Bulgaresi P, Maddau C, Turco P, Houssami N. Accuracy of fine needle aspiration cytology (FNAC) of axillary lymph nodes as a triage test in breast cancer staging. Breast Cancer Res Treat. 2007;103(1):85-91. https://doi.org/10.1007/s10549-006-9355-0. 
19. Gipponi M, Fregatti P, Garlaschi A, Murelli F, Margarino C, Depaoli F, Baccini P, Gallo M, Friedman D. Axillary ultrasound and Fine-Needle Aspiration Cytology in the preoperative staging of axillary node metastasis in breast cancer patients. Breast. 2016;30:146-50. https://doi.org/10.1016/j.breast.2016.09.009.

20. Vidya R, Bickley B. Pre-operative axillary staging: should core biopsy be preferred to fine needle aspiration cytology? 2017. https://doi.org/10.3332/ ecancer.2017.724.

21. Zhang F, Zhang J, Meng Q-X, Zhang X. Ultrasound combined with fine needle aspiration cytology for the assessment of axillary lymph nodes in patients with early stage breast cancer. Medicine. 2018;97(7):e9855. https:// doi.org/10.1097/MD.0000000000009855.

22. Nakamura R, Yamamoto N, Miyaki T, Itami M, Shina N, Ohtsuka M. Impact of sentinel lymph node biopsy by ultrasound-guided core needle biopsy for patients with suspicious node positive breast cancer. Breast Cancer. 2018; 25(1):86-93. https://doi.org/10.1007/s12282-017-0795-7.

23. You S, Kang DK, Jung YS, An Y-S, Jeon GS, Kim TH. Evaluation of lymph node status after neoadjuvant chemotherapy in breast cancer patients: comparison of diagnostic performance of ultrasound, MRI and ${ }^{18} \mathrm{~F}-\mathrm{FDG}$ PET/ CT. Br J Radiol. 2015;88(1052):20150143. https://doi.org/10.1259/bjr.20150143.

24. Le-Petross HT, McCall LM, Hunt KK, Mittendorf EA, Ahrendt GM, Wilke LG, Ballman KV, Boughey JC. Axillary Ultrasound Identifies Residual Nodal Disease After Chemotherapy: Results From the American College of Surgeons Oncology Group Z1071 Trial (Alliance). AJR. Am J Roentgenol. 2018;210(3):669-76. https://doi.org/10.2214/AJR.17.18295.

25. Baumgartner A, Tausch C, Hosch S, Papassotiropoulos B, Varga Z, Rageth C, Baege A. Ultrasound-based prediction of pathologic response to neoadjuvant chemotherapy in breast cancer patients. Breast. 2018;39:19-23. https://doi.org/10.1016/j.breast.2018.02.028.

26. Loibl S, Volz C, Mau C, Blohmer JU, Costa SD, Eidtmann H, Fasching PA, Gerber B, Hanusch C, Jackisch C, Kümmel S, Huober J, Denker C, Hilfrich J, Konecny GE, Fett W, Stickeler E, Harbeck N, Mehta KM, Nekljudova V, Minckwitz vonG, Untch M. Response and prognosis after neoadjuvant chemotherapy in 1,051 patients with infiltrating lobular breast carcinoma. Breast Cancer Res Treat. 2014;144(1): 153-62. https://doi.org/10.1007/s10549-014-2861-6.

27. Rao R, Lilley L, Andrews V, Radford L, Ulissey M. Axillary staging by percutaneous biopsy: Sensitivity of fine-needle aspiration versus core needle biopsy. Ann Surg Oncol. 2009;16(5):1170-5. https://doi.org/10.1245/s10434009-0421-9.

28. Zhu Y, Zhou JQ, Jia XH, Zhou W, Zhan WW. Interobserver variability between experienced radiologists in evaluating the number of abnormal lymph nodes seen on preoperative axillary ultrasound. Clin Radiol. 2021; 76(1):60-6. https://doi.org/10.1016/j.crad.2020.03.041.

29. Forgia D, La, Fausto A, Gatta G, Di Grezia G, Faggian A, Fanizzi A, Cutrignelli D, Dentamaro R, Didonna V, Lorusso V, Massafra R, Tangaro S, Mazzei MA, Elite. VABB 13G: A New Ultrasound-Guided Wireless Biopsy System for Breast Lesions. Technical Characteristics and Comparison with Respect to Traditional Core-Biopsy 14-16G Systems. 2020;10:291. https://doi.org/10.33 90/diagnostics10050291.

30. Fanizzi A, Pomarico D, Paradiso A, et al. Predicting of Sentinel Lymph Node Status in Breast Cancer Patients with Clinically Negative Nodes: a Validation Study. Cancers (Basel). 2021;19(2):352. https://doi.org/10.3390/cancers13020352.

31. Nielsen Moody A, Bull J, Culpan AM, Munyombwe T, Sharma N, Whitaker M, Wolstenhulme $\mathrm{S}$. Preoperative sentinel lymph node identification, biopsy and localisation using contrast enhanced ultrasound (CEUS) in patients with breast cancer: a systematic review and meta-analysis. Clin Radiol. 2017; 72(11):959-71. https://doi.org/10.1016/j.crad.2017.06.121.

32. Wojcinski S, Dupont J, Schmidt W, Cassel M, Hillemanns P. Real-Time Ultrasound Elastography in 180 Axillary Lymph Nodes: Elasticity Distribution in Healthy Lymph Nodes and Prediction of Breast Cancer Metastases. MC Med Imaging. 2012;19(12):35. https://doi.org/10.1186/1471-2342-12-35.

33. Park YM, Fornage BD, Benveniste AP, Fox PS, Bassett RL, Yang WT. Strain elastography of abnormal axillary nodes in breast cancer patients does not improve diagnostic accuracy compared with conventional ultrasound alone. AJR Am J Roentgenol. 2014;203(6):1371-8. https://doi.org/10.2214/A JR.13.12349

\section{Publisher's Note}

Springer Nature remains neutral with regard to jurisdictional claims in published maps and institutional affiliations.

Ready to submit your research? Choose BMC and benefit from:

- fast, convenient online submission

- thorough peer review by experienced researchers in your field

- rapid publication on acceptance

- support for research data, including large and complex data types

- gold Open Access which fosters wider collaboration and increased citations

- maximum visibility for your research: over $100 \mathrm{M}$ website views per year

At $\mathrm{BMC}$, research is always in progress.

Learn more biomedcentral.com/submissions 